\title{
Exceptional tensile properties under cryogenic temperature in heterogeneous laminates induced by non-uniform martensite transformation and strain delocalization
}

\author{
Jinyan He ${ }^{\mathrm{a}, \mathrm{b}}$, Fuping Yuan ${ }^{\mathrm{a}, \mathrm{b}, *}$, Muxin Yang ${ }^{\mathrm{a}}$, Lingling Zhou ${ }^{\mathrm{a}}$, Sihai Jiao ${ }^{\mathrm{c}}$, Xiaolei Wu ${ }^{\mathrm{a}, \mathrm{b}}$ \\ a State Key Laboratory of Nonlinear Mechanics, Institute of Mechanics, Chinese Academy of Science, 15 Beisihuan West Road, Beijing, 100190, China \\ ${ }^{\mathrm{b}}$ School of Engineering Science, University of Chinese Academy of Sciences, 19A Yuquan Road, Beijing, 100049, China \\ ${ }^{c}$ Baosteel Research Institute, Baoshan Iron \& Steel Co Ltd, Shanghai, 201900, China
}

\section{A R T I C L E I N F O}

\section{Keywords:}

Twins

Heterogeneous laminates

Cryogenic tensile properties

Martensite transformation

Strain delocalization

\begin{abstract}
A B S T R A C T
In the present study, the heterogeneous low $\mathrm{C}$ steel/304 austenite stainless steel (SS) laminates were observed to have exceptional tensile properties under cryogenic temperature, i.e., the yield strength and the uniform elongation were found to be significantly elevated simultaneously compared to these under room temperature. The underlying deformation mechanisms have been revealed by a novel tensile testing method coupled with in-situ digital image correlation imaging under cryogenic environment, and subsequent microstructure observations. Strain localization was found to initiate from low C steel, propagate across the interface and then towards 304 SS side. While the formed localized strain zone (LSZ) was observed to be delocalized at larger tensile strain due to the propagation of LSZ towards the un-deformed region along the gage length. Martensite transformation was found to be concentrated in the LSZ of 304 SS to regain strain hardening ability and reduce severity of strain concentration. Strain partitioning between 304 SS and low C steel was found to be more significant in the LSZ than that out of the LSZ. The non-uniform martensite transformation along the gage length should be the origin for the strain delocalization in the LSZ, resulting in large ductility in the laminates under cryogenic temperature.
\end{abstract}

\section{Introduction}

Structural materials have been designed for cryogenic applications, such as liquid Nitrogen/Hydrogen storage tanks and cryogenic processing [1-19]. For example, high manganese twinning-induced plasticity (TWIP) steels [1-7] and stainless steels (SS) [8-17] have been widely accepted as ideal candidate materials for cryogenic applications due to the excellent mechanical properties with high strength, enhanced strain-hardening rate and good tensile ductility at cryogenic temperatures. In these steels, the deformation mechanisms of transformation-induced plasticity (TRIP) and TWIP usually become more dominant with decreasing temperature due to the even lower stacking fault energy (SFE) at cryogenic temperatures, resulting in more obvious strain hardening [1,9]. These TWIP steels and SS generally show a significant discontinuous strain hardening phenomenon at the cryogenic condition: After initial yielding, a gentle slope of first hardening or a plateau stage continues until the critical tensile strain for the onset of the second hardening induced by TWIP/TRIP effects $[8,9]$.

Although the yield strength and the strain-hardening rate have been found to be elevated for TWIP steels and SS with decreasing temperature, the uniform elongation has been observed to be lower at cryogenic temperatures compared to that at room temperature $[1,2,8,9,17]$. Moreover, the yield strength is relatively low for the TWIP steels and SS with coarse grains, which limits their structural applications. It is well known that the strength of metals and alloys can be much elevated by cold-working or grain refinement $[20,21]$. While the elevated high yield strength through this way in homogeneous microstructures usually results in significantly reduced tensile ductility [20-22]. In last two decades, extensive research have indicated that heterogeneous microstructures can be considered as a useful strategy to resolve the observed dilemma of strength-ductility trade-off [22-45]. Among these heterogeneous microstructures, bimetallic laminates have attracted extensive interests recently due to the fact that superior tensile properties can be achieved and be optimized by tailoring microstructures

\footnotetext{
* Corresponding author. State Key Laboratory of Nonlinear Mechanics, Institute of Mechanics, Chinese Academy of Science, 15 Beisihuan West Road, Beijing, 100190, China.

E-mail address: fpyuan@lnm.imech.ac.cn (F. Yuan).
} 
across interfaces in the laminates [25-32]. The enhanced tensile ductility in the laminates can be attributed to the extra strain hardening induced by the strain gradients and geometrically necessary dislocations (GNDs) at the interfaces, which are typically generated due to the mechanical incompatibility and stress/strain partitioning between soft and hard domains under tensile loading [32-35,45].

In our recent work [34], we have indicated that the $304 \mathrm{SS} /$ low C steel (with martensite phase) laminates can have a much higher yield strength and an acceptable ductility at room temperature when compared to the single 304 SS sample. While no phase transformation was observed in the 304 SS during the tensile loading for the laminates at room temperature, thus the tensile ductility might be further improved if the phase transformation can be activated in the 304 SS at cryogenic temperature. Previous research also shown that the yield strength can be much higher and the uniform elongation was also observed to be slight higher for BCC single phase steels (martensite) or dual phase steels (ferrite and martensite) at cryogenic temperatures, compared to those at room temperature $[18,19]$. These observations give a hint that exceptional tensile properties might be achieved in the 304 SS/low C steel laminate at cryogenic temperature due to its heterogeneous nature, thus giving better performance under cryogenic applications. In this regard, the tensile properties and the detailed deformation mechanisms of the $304 \mathrm{SS} /$ low C steel laminates at $77 \mathrm{~K}$ have been investigated by a novel well-designed tensile testing method coupled with in-situ digital image correlation (DIC) imaging under cryogenic environment and subsequent microstructure characterizations.

\section{Materials and experimental methods}

The laminates were produced by hot-rolling (HR) technique, and the constitute plates were two 304 SS steel plates (with chemical composition of $0.05 \mathrm{C}-1.2 \mathrm{Mn}-19 \mathrm{Cr}-10 \mathrm{Ni}-69.75 \mathrm{Fe}$, in weight percentage) and one low $\mathrm{C}$ steel plate (with chemical composition of $0.2 \mathrm{C}-1.0 \mathrm{Mn}-0.02 \mathrm{Ti}-$ $0.04 \mathrm{Nb}-98.74 \mathrm{Fe}$, in weight percentage) sandwiched in between. The thickness ratio between the 304 SS steel plate and the low C steel plate was $1: 8$, and the total thickness for the three sandwiched plates before HR was about $10 \mathrm{~mm}$. The HR process was under the temperature range between $1423 \mathrm{~K}$ and $1173 \mathrm{~K}$, and the resultant HR laminates had a thickness of about $3.34 \mathrm{~mm}$. Then cold-rolling (CR) processing was utilized to further reduce the thickness of the laminates to about $1.5 \mathrm{~mm}$. Finally, the CR plates were annealed at $1193 \mathrm{~K}$ for $15 \mathrm{~min}$ followed immediately by water quenching (WQ). The purpose of annealing and WQ is to obtain recrystallized austenite phase in 304 SS and martensite phase in low C steel. For comparison, the homogeneous standalone 304 SS steel plate and the homogeneous standalone low C steel plate were also obtained by polishing away the other part of the laminates.

The dog-bone shaped plate specimens for tensile testing had gauge section dimensions of $10 \times 2.5 \times 1.5 \mathrm{~mm}^{3}$. The longitudinal axis was set to be parallel to the rolling direction. Using a MTS Landmark testing machine, the quasi-static uniaxial tensile tests were carried out at a strain rate of $5 \times 10^{-4} \mathrm{~s}^{-1}$ under displacement control at both room and cryogenic temperatures. For each experiment, three tests were applied to check the repeatability and provide the error bar. An extensometer was utilized in all tensile tests to monitor the displacement accurately. DIC imaging was performed on the surface 304 SS layer to measure the strain contours during tensile deformation at cryogenic temperature. The configuration for the in-situ tensile testing coupled with DIC imaging under low temperature is shown in Fig. 1. The whole system mainly consists of a mechanical testing machine, a cooling system and a DIC imaging system. The universal machine provides tensile load to the testing sample, the cooling system provides cryogenic environment with tunable temperatures, whereas the DIC imaging system measures the strain contours during tensile deformation. The samples were cooled down by two Gifford-McMahon (G-M) cryocoolers, and the cooling process was characterized by cooling with recycled helium gas as heat

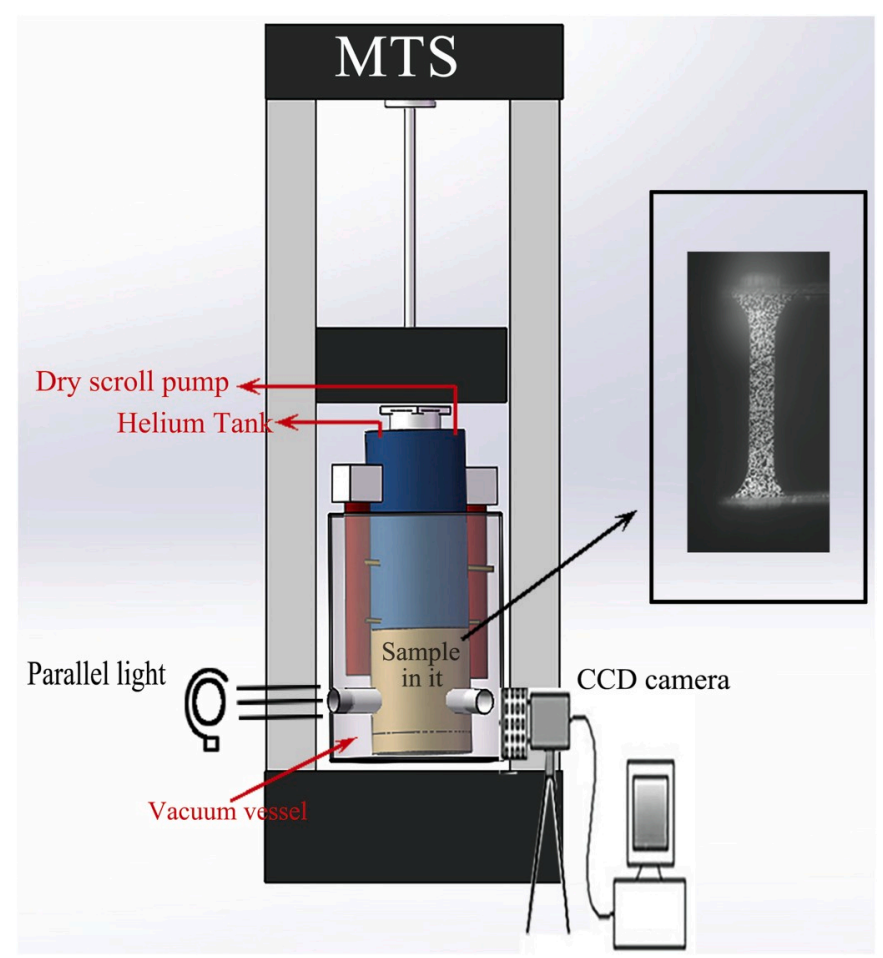

Fig. 1. Configuration for the in-situ tensile testing coupled with DIC imaging under low temperature environment.

transfer medium instead of liquid helium. The optimal temperature range for operation of G-M cryocoolers is between 12 and $120 \mathrm{~K}$, the working principle of the G-M cryocooler is based on refrigeration by outglassing of adiabatic gas. Agilent SHI 110 dry scroll pump was also used to draw out helium gas in sample chamber in the decompression process in order to make sure that the sample surface is clean to be observed by the camera for DIC imaging system. The other details about the cooling system can be referred to the previous paper [46]. As shown in Fig. 1, the initial high-contrast stochastic spot patterns were created on the sample surface, a commercial software ARAMIS was utilized to analyze the DIC data and the used facet size for the strain calculation was $50 \mu \mathrm{m}$, and the other details for the DIC imaging system can be found elsewhere [47]. The micro-hardness distributions at the area close to the interface prior to and after tensile testing were measured on the well-polished specimens by a Vickers diamond indenter under a load of $5 \mathrm{~g}$ for $15 \mathrm{~s}$ dwell time. Ten groups of indentations were conducted for each point, and the average value was used with a provided error bar.

Optical microscopy (OM), electron back-scattered diffraction (EBSD), and transmission electron microscopy (TEM) were utilized to reveal the microstructures prior to and after tensile testing. The information of phase transformation for the 304 SS in the laminates during tensile deformation at low temperature were obtained on the polished samples by X-ray diffraction (XRD) measurements and EBSD observations. The phase volume fractions were estimated from the peak integrated intensities $\mathrm{I}_{\mathrm{hkl}}$ after background subtraction. The details for XRD measurements and the calculation method for the volume fractions of each phase can be found in previous papers $[47,48]$. The sample preparations for EBSD and TEM can be referred to our previous paper [34]. In EBSD observation, a small scanning step of $100 \mathrm{~nm}$ was utilized and grain boundaries (GBs) were only identified when the misorientation angles are larger than $15^{\circ}$. Calculation method for kernel average misorientation (KAM) can also be found in our previous research [34].

\section{Results and discussions}

Microstructures of the laminate prior to tensile testing have been 
characterized by OM, EBSD, and TEM. OM image for the whole laminate is displayed in Fig. 2a, in which two layers of $304 \mathrm{SS}$ and one layer of low $\mathrm{C}$ steel can be clearly observed, and the straight layer boundaries can be obviously identified. EBSD image (phase distribution with GBs) for the area close to the interface is displayed in Fig. 2b. After WQ, a grain size gradient is observed at the side of 304 SS austenite phase, i.e., the grain size increases with increasing distance from the interface, which is consistent with the hardness distribution in Fig. 2c. The average grain size for the $304 \mathrm{SS}$ at the interface is about $300 \mathrm{~nm}$, which is much smaller compared to the average grain size of $20 \mu \mathrm{m}$ at the position far away from the interface. No martensite phase is observed at the side of 304 SS. While lath martensite (as shown in the inset of Fig. 2b and f) is formed in the low C steel after WQ, and the feature size of lath martensite is similar along the depth. The micro-hardness distribution across the interface for the laminate is shown in Fig. 2c, in which the hardness values at both sides of the interface show a gradient distribution. The hardness decreases with increasing distance from the interface at the side of 304 SS, while the hardness gradually increases with increasing distance from the interface at the side of low $\mathrm{C}$ steel. For both sides, the hardness is observed to approach a plateau when the location is far away from the interface, and the plateau value of the low C steel side is much higher than that of the 304 SS side. The gradient distribution for the hardness near the interface at the side of low $C$ steel can be attributed to the volume fraction gradient of martensite phase due to the $\mathrm{C}$ diffusion from the side of low C steel to the side of 304 SS during heat treatment [34].

The TEM image for the area close to the interface is displayed in Fig. 2d. The interface separating the low $\mathrm{C}$ steel and the $304 \mathrm{SS}$ is marked by a dash line. The selected area diffractions (SAD) for the low C steel and the 304 SS (for two circled areas) are also shown in Fig. 2d. Moreover, TEM images for the $304 \mathrm{SS}$ side at the interface and the low C steel side are shown in Fig. 2e and f, respectively. The SAD for the 304 SS in the inset in Fig. 2e shows that the 304 SS has a austenite phase and consists of annealing twins. The grains in Fig. 2e are ultrafined grains and the annealing twins can be clearly observed. The lath martensite are also ultrafined grains, and the width of the lath martensite grains can be estimated to be about $250 \mathrm{~nm}$ based on the observations and the statistical analysis of numerical TEM images.

The tensile properties for the laminate and the corresponding standalone plates under low temperature $(77 \mathrm{~K})$ and room temperature are shown in Fig. 3. The engineering stress-strain curves are displayed in Fig. 3a, and the curves for the yield strength vs. the uniform elongation for all samples are shown in Fig. 3c. It can be clearly observed that the standalone 304 SS plate has a higher yield strength, a higher strain hardening ability and a lower uniform elongation under cryogenic temperature compared to these under room temperature. It is clearly shown that the yield strength is higher and the uniform elongation is also slightly larger for the low $\mathrm{C}$ steel under cryogenic temperature compared to these under room temperature. In sharp contrast, the yield strength and the uniform elongation are both observed to be significantly higher for the laminate under low temperature compared to these under room temperature. These observations indicate that exceptional tensile properties can be induced under cryogenic temperature in the laminate, as compared to the standalone plates. As shown in the close-up view of the engineering stress-strain curve for the laminate under low temperature, a stress plateau is observed after yielding, followed by a strong strain hardening stage (as shown in Fig. 3b). In order to understand the deformation mechanisms for the superior cryogenic tensile properties and the stress plateau phenomenon in the laminate, the in-situ DIC experiments on the sample surface, the microstructure characterizations by EBSD, XRD and TEM at various tensile strains by interrupting experiments were also carried out.

A series of typical longitudinal tensile strain $\left(\varepsilon_{\mathrm{L}}\right)$ contour maps at various applied tensile strains ( $\varepsilon_{\text {app }}$, corresponding to the points marked by arrows in the engineering stress-strain curve in Fig. 4b) for the surface of $304 \mathrm{SS}$ in the laminate are displayed in Fig. 4a. At $\varepsilon_{\mathrm{app}}=2.6 \%$, a relatively uniform strain contour can be observed in Fig. 4a since the stress is still rising at this applied stain as shown in Fig. 4b. While a localized strain zone (LSZ) is formed at the lower part of the gage-section when $\varepsilon_{\text {app }}=4.4 \%$, which can be connected to the slight stress drop at this strain as shown in Fig. 4b. As observed, the LSZ carries the most plastic strain and accumulates plastic strain continuously, Fig. 4c displays the heterogeneous $\varepsilon_{\mathrm{L}}$ distributions along the gage length at various applied tensile strains ( $\left.\varepsilon_{\mathrm{app}}\right)$, as a result of the propagating LSZ. In Fig. $4 c, \varepsilon_{\mathrm{L}}$ is averaged along the width of the sample in each contour. Here, we define the LSZ as the zone with $\varepsilon_{\mathrm{L}}>\varepsilon_{\text {app }}$. Thus, the length of LSZ can be identified by the distance of two " $\times$ " marked in each curve of Fig. 4c. The normalized length of LSZ as a function of the applied tensile a

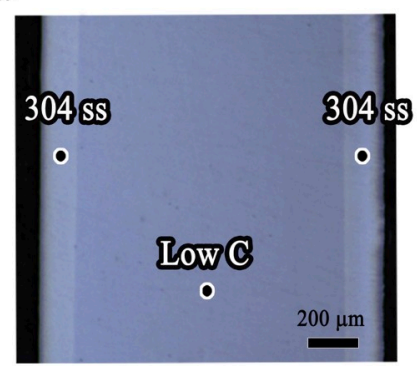

d

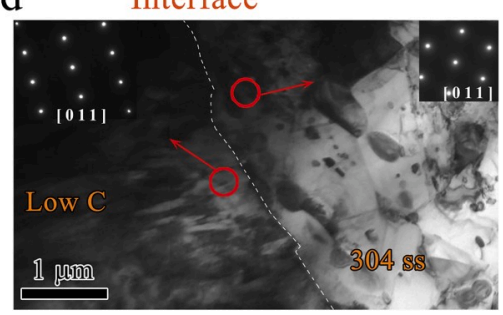

b

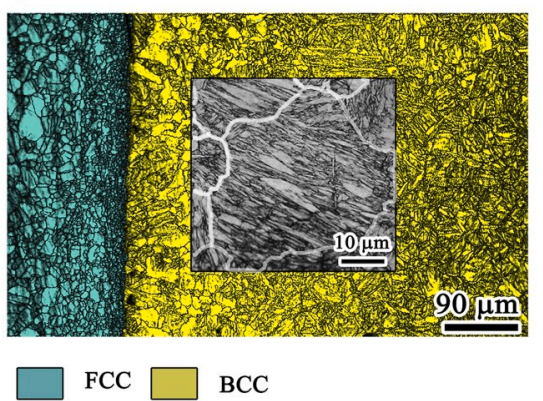

e

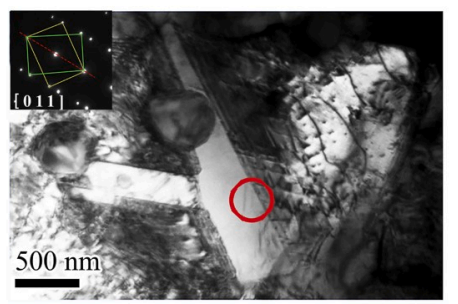

c

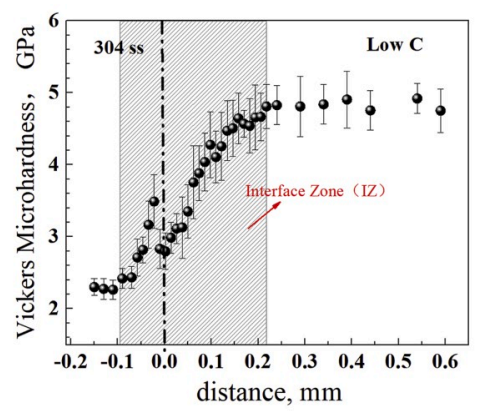

f

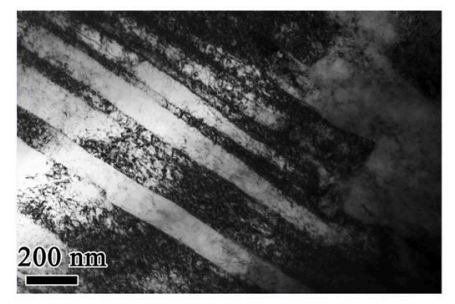

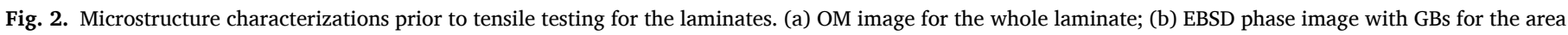

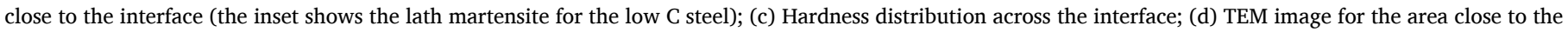
interface (the interface is marked by a dashed line); (e) TEM image for the 304 SS side at the interface; (f) TEM image for the low C steel side at the interface. 

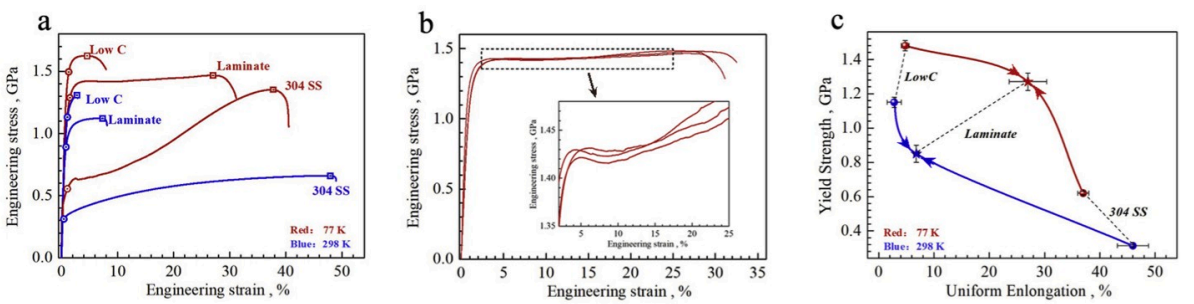

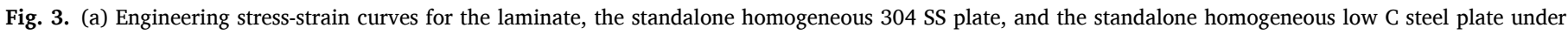

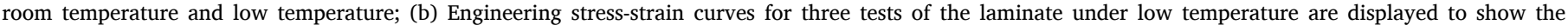
repeatability, and the inset shows the plateau stage followed by strain hardening stage; (c) The yield strength vs. the uniform elongation for all samples.

a
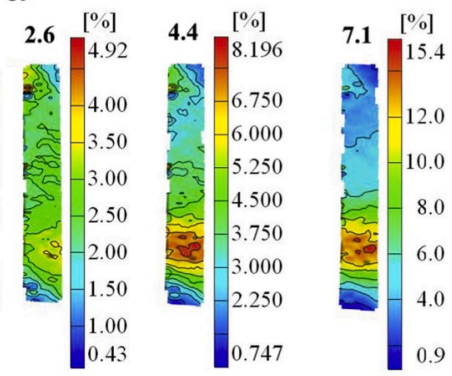

c

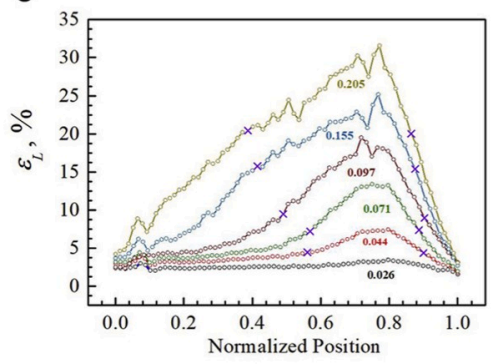

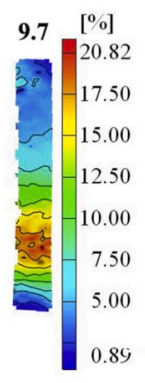
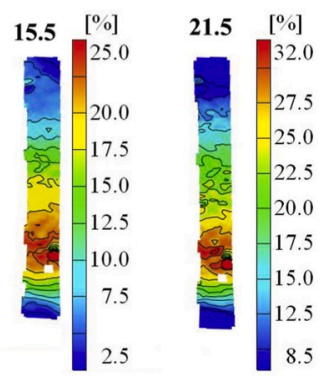

b
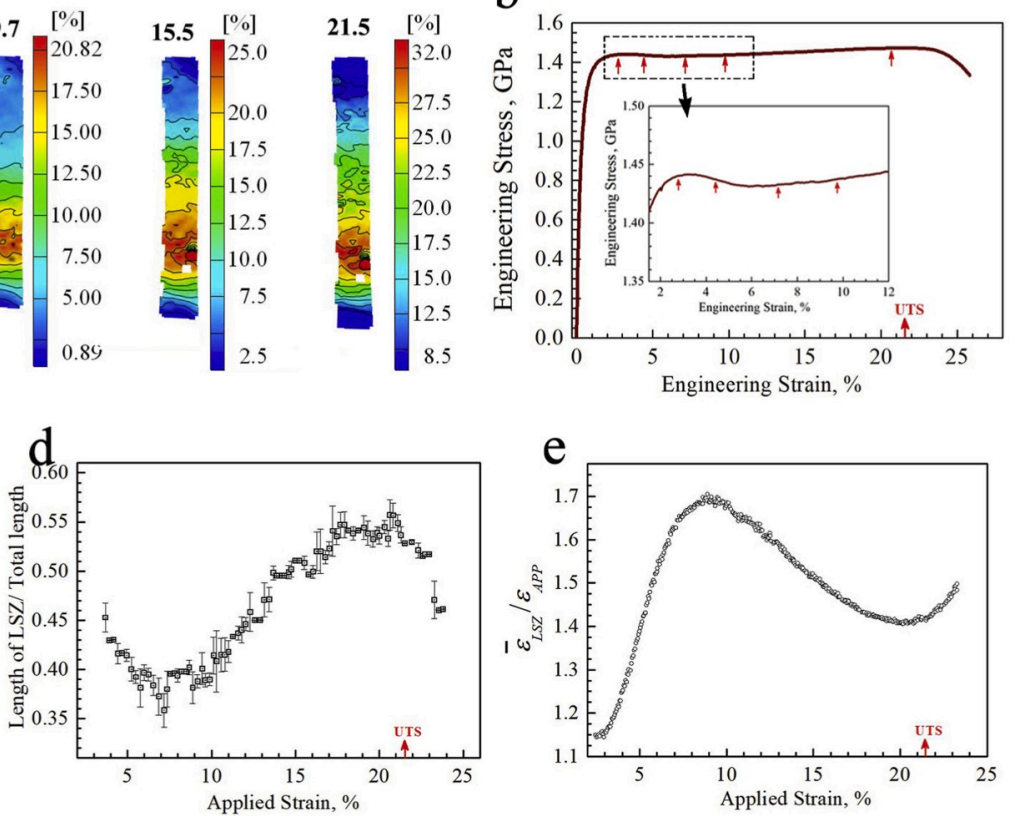

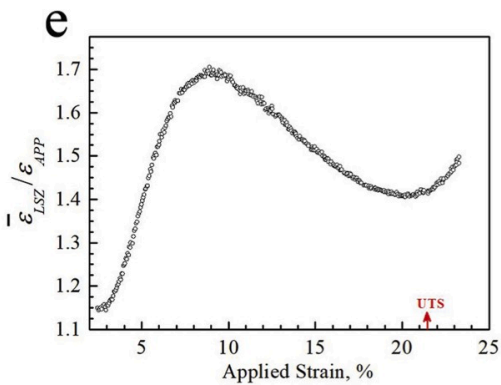

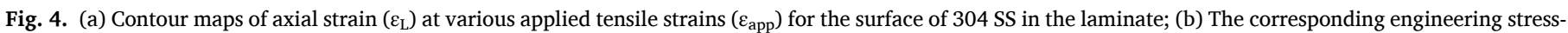

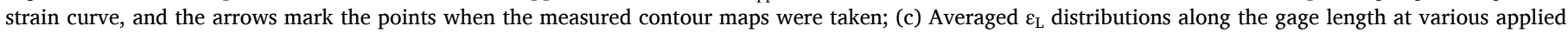

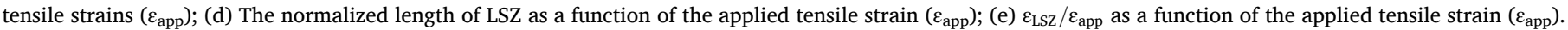

strain is shown in Fig. 4d. Starting from $\varepsilon_{\text {app }}=2.6 \%$, the length of LSZ first slightly decreases due to the initial strain localization until $\varepsilon_{\text {app }} \approx$ $9 \%$, where the LSZ starts to propagate along the gage length. From $\varepsilon_{\text {app }}$ $\approx 9 \%$, the LSZ propagates fast first, and then slows down later, as indicated by the slope in the curve of Fig. 4d. Moreover, the ratio between the average longitudinal strain in the LSZ and the applied tensile strain $\left(\bar{\varepsilon}_{\mathrm{LSZ}} / \varepsilon_{\mathrm{app}}\right)$ can be considered as an indicator on the severity of the strain localization in the LSZ. Thus, $\bar{\varepsilon}_{\mathrm{LSZ}} / \varepsilon_{\mathrm{app}}$ as a function of the applied tensile strain is plotted in Fig. 4e. It is clearly indicated that the strain localization starts at a very low applied tensile strain $(\sim 2 \%)$, reaches its maximum at $\varepsilon_{\mathrm{app}} \approx 9 \%$, and then decreases with increasing applied tensile strain until the ultimate strength (UTS) point. These observations indicate that the strain starts to concentrate in the LSZ at the low applied strain, while the strain localization starts to delocalize and the severity of strain concentration starts to alleviate in the LSZ at larger applied tensile strain due to the propagation of LSZ towards the un-deformed region along the gage length.

In order to connect the strain distribution to the phase transformation distribution along the gage length, and reveal the origin of the strain de-localization, the volume fraction distributions of martensite (measured by XRD or EBSD) along the gage length at various applied tensile strains, for the surface of 304 SS and the area close to the interface for 304 SS in the laminate, are shown in Fig. 5. The typical profiles for the evolution of XRD spectra at the fixed normalized position (0.4) on the surface of $304 \mathrm{SS}$ are displayed in Fig. 5b. The profiles of the XRD spectra evolution for the other positions are not shown here due to the limitation of space. The volume fraction distribution of martensite along the gage length on the surface for the 304 SS were measured by XRD method (Fig. 5b), while the volume fractions of martensite for the 304 SS in and out the position of the LSZ at the area close to the interface were characterized by EBSD (Fig. 5c). As shown in Fig. 5c, it can be clearly seen that the volume fraction distributions of martensite along the gage length on the surface are relatively uniform along the gage length when the applied tensile strain is $7 \%$, while this martensite phase distribution starts to concentrate in the LSZ from $\varepsilon_{\text {app }}=10 \%$. Due to this concentration of martensite transformation in the LSZ, and the strain hardening ability is regained in the LSZ to reduce the strain localization and force the LSZ to propagate towards the un-deformed region. Thus, the non-uniform martensite transformation along the gage length should be the origin for the strain de-localization in the LSZ. And this nonuniform martensite transformation induced strain de-localization in the LSZ should help to achieve large tensile ductility in the laminate.

In the laminate, the low $\mathrm{C}$ steel layer has higher strength and lower strain hardening ability when compared to the 304 SS layer subjected to cryogenic tensile deformation. Thus, one may imagine that the strain localization should start at the side of low $\mathrm{C}$ steel first and propagate 


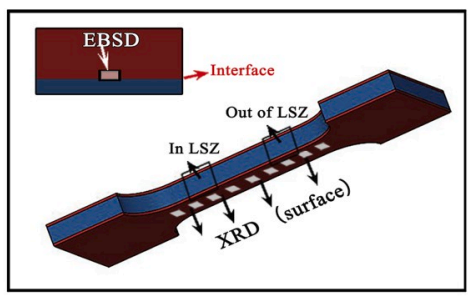

b
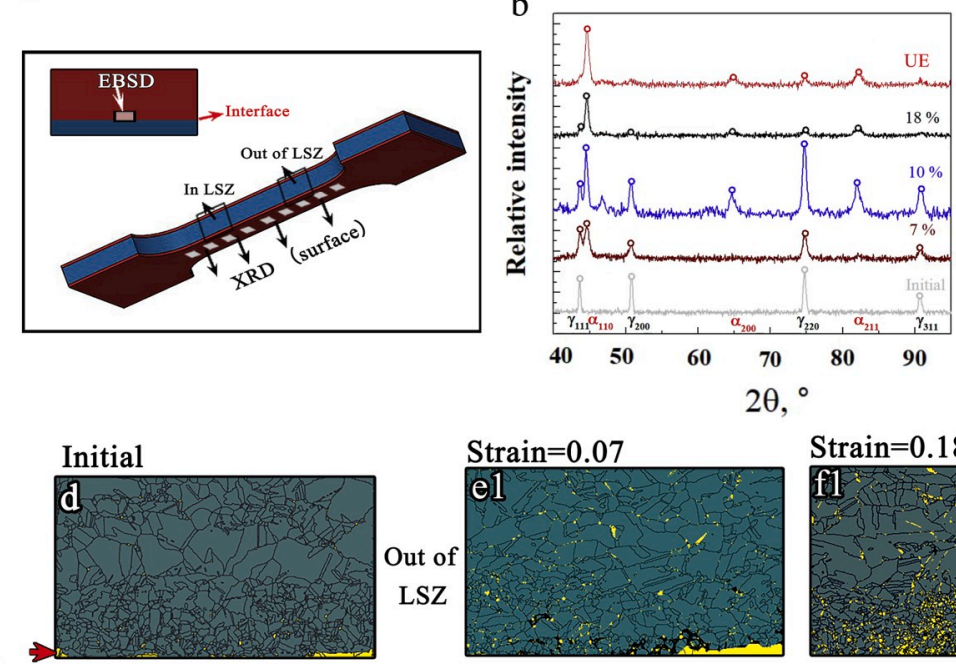

Interface

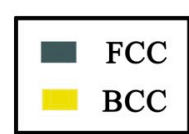

In LSZ

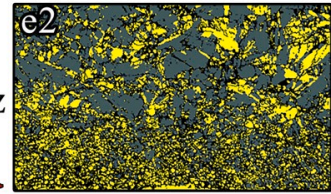

Interface
Strain $=0.18$
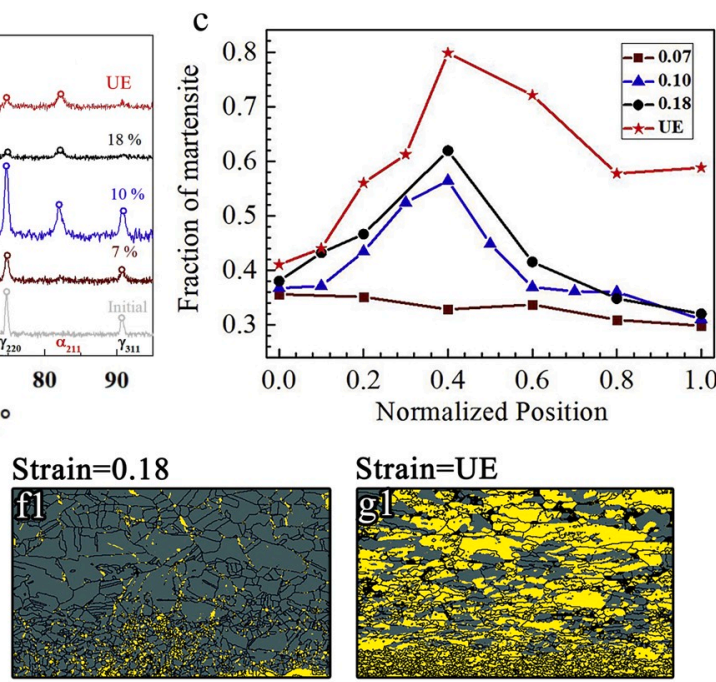

Strain $=\mathrm{UE}$
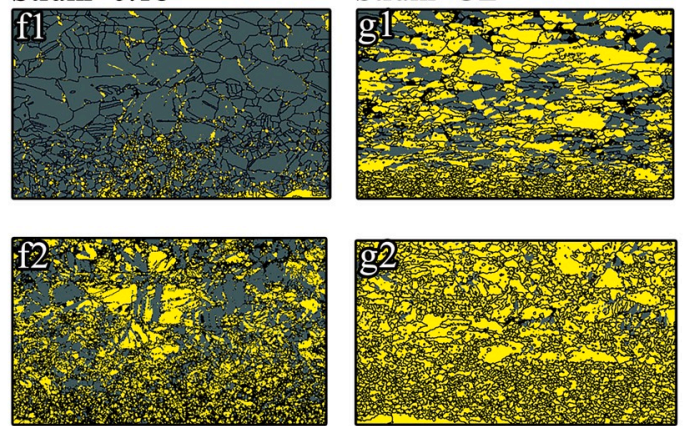

$10 \mu \mathrm{m}$ $\mathrm{h}$

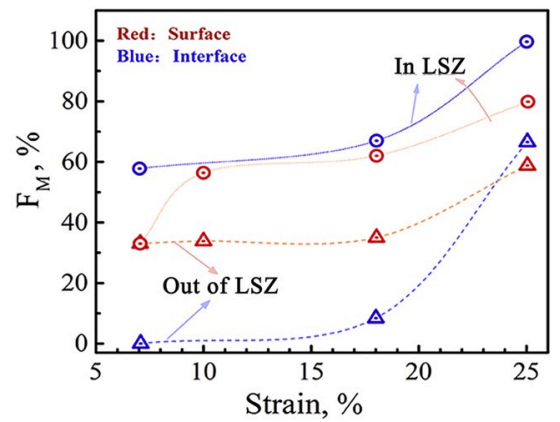

i

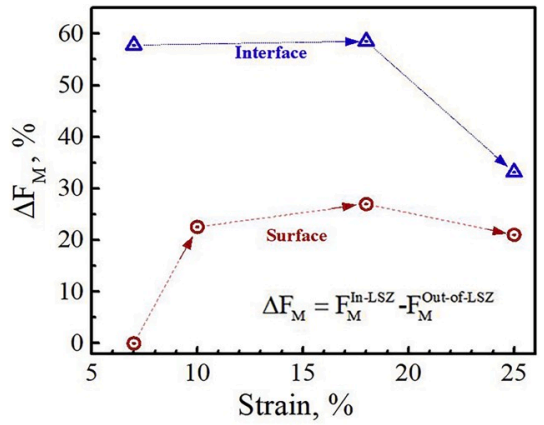

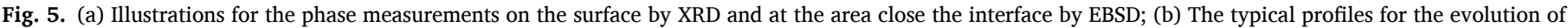

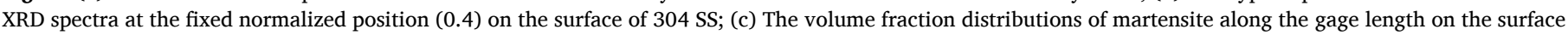

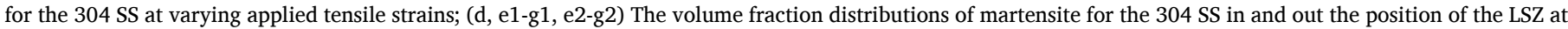

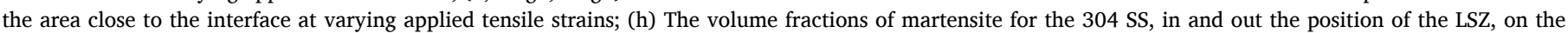

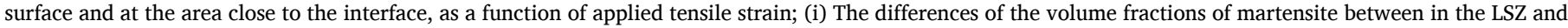
out the LSZ $\left(\Delta \mathrm{F}_{\mathrm{M}}\right)$ as a function of applied tensile strain for the surface and the area close to the interface.

across the interface, and then towards the side of 304 SS. To verify this, we also check the volume fraction distributions of martensite along the gage length at various applied tensile strains for the 304 SS close to the interface (Fig. 5d, e1-5g1 and 5e2-5g2). The initial EBSD phase image for the undeformed sample is displayed in Fig. 5d. In Fig. 5e1-5g1, the EBSD phase images for the 304 SS close to the interface at the gage length position similar to the LSZ on the surface are displayed, while Fig. 5e2-5g2 show EBSD phase images for the 304 SS close to the interface at the gage length position far from the initial LSZ. It can be clearly observed that the non-uniform martensite transformation along the gage length in the 304 SS starts earlier for the area close to interface, when compared to the surface ( $7 \%$ vs. $10 \%$, as shown in Fig. $5 \mathrm{~h}$ ). It is generally known that the phase stability of austenite increases with increasing carbon content $[49,50]$. This fact may delay to trigger the uniform martensite transformation in 304 SS for the area close to the interface compared to that at the surface. Indeed, as shown in Fig. 5h, it is observed that no martensite transformation occurs until tensile strain of $18 \%$ out of the LSZ at the area close to the interface. While the non-uniform martensite transformation should be induced mainly by the strain localization along the gage length. Thus, the non-uniform martensite transformation is observed to be triggered earlier for the 304 SS close to the interface due to the earlier strain concentration, when compared to the 304 SS at the surface. These observations verify that the low $\mathrm{C}$ steel with higher strength and lower strain hardening ability should start strain localization first, and then this strain localization should propagate across the interface and towards to the 304 SS side (from the interface to the surface). The differences of the volume fractions of martensite between in the LSZ and out the LSZ $\left(\Delta \mathrm{F}_{\mathrm{M}}\right)$ can be considered as an indicator of severity of the non-uniform martensite transformation, which are plotted as a function of applied tensile strains for the surface and the area close to the interface in Fig. 5i. It can be clearly indicated that the severity of the non-uniform martensite transformation along the gage length is much larger for the area close to the interface compared to the surface, which can be attributed to the fact that the area close to the interface is adjacent to the more unstable low $\mathrm{C}$ steel layer. Thus, the more severe non-uniform martensite 
transformation for the 304 SS at the area close to the interface is needed to overcome the unstable plastic flow in the low $\mathrm{C}$ steel. $\Delta \mathrm{F}_{\mathrm{M}}$ for both the surface and the area close to the interface start to decrease at larger applied strains and start to lose the advantage of non-uniform martensite transformation for helping ductility, thus resulting in final necking and fracture at the initial LSZ position at UTS point.

The hardness increment after tensile deformation can usually be considered to be an indicator of strain hardening capability, thus the Vickers microhardness $(\mathrm{Hv})$ distributions across the interface in and out of the position of the LSZ at varying applied tensile strains are provided in Fig. 6. For the side of 304 SS, the hardness of LSZ increases significantly at the applied tensile strain of $7 \%$ (due to the strain concentration in the LSZ), then increases slightly afterwards (the strain magnitude in the LSZ increases slightly due to the propagation of the LSZ towards the undeformed region) until UTS point. While the hardness for 304 SS out of the LSZ increases more or less equally before and after the applied tensile strain of $7 \%$. For the side of low $\mathrm{C}$ steel, the hardness increment out of the LSZ is larger than that in the LSZ at the applied tensile strain of $7 \%$, which might be due to the fact that the strain partitioning between 304 SS and low C steel is more significant in the LSZ (the low C steel in the LSZ carries much less strain) than that out of the LSZ (which will be confirmed by the KAM distribution maps in Fig. 7). Moreover, the hardness for the low C steel in the LSZ starts to decrease after the applied tensile strain of $7 \%$, which might be due to the change of strain path and stress state $[27,51]$ by the propagation of the LSZ along the gage length. Previous research have indicated that the change of strain path and stress state can cause dismantlement of existing dislocation substructure and reduce the dislocation density $[27,51]$. These observation will be further confirmed by subsequent TEM observations for low $\mathrm{C}$ steel.

As indicated in the previous research [24,32-35], strain partitioning across the interfaces between hard layers and soft layers should result in strong strain gradient across the interfaces, which can be reflected by GND density distributions across the interfaces. Moreover, the local crystal orientations by the KAM method in the EBSD images can be used to calculate the GND density based on the strain gradient theory, which was proposed by Gao and Kubin [52,53], in which the KAM value is linearly proportional to the GND density. Thus, the KAM value can reflect directly the GND density. The KAM distributions in the 304 SS at the area close to the interface in and out of the LSZ are displayed in Fig. 7. The initial KAM distribution map for the undeformed sample is shown in Fig. 7a. As shown in Fig. 7a, a relatively low GND density also exists in the area near the interface for the sample prior to tensile testing. This GND distribution in the area near the interface could be attributed to the internal residual stress induced by the different thermal expansions between the 304 SS and the low C steel during heat treatment process. As indicated in our previous paper [34], these initial internal residual stresses should have impact on the nature of the elastoplastic transition stage and provide the initial back stress for strengthening. While, the back stress increment upon applied tensile strain (back stress hardening) should mainly be attributed to the plastic deformation incompatibility between different layers during the tensile loading, resulting in extra hardening for improving ductility. The KAM distribution maps in and out of the LSZ at varying applied tensile strains (7\%, $18 \%$ and UTS point) are shown in Fig. $7 \mathrm{~b} 1-7 \mathrm{~d} 1$ and $7 \mathrm{~b} 2-7 \mathrm{~d} 2$, respectively. Then, the KAM value is averaged at the same distance from the interface, and this averaged KAM value is plotted as a function of the distance from the interface at varying applied tensile strains in and out of the LSZ in Fig. 7e and f, respectively. The mean KAM values for the whole map are also plotted as a function of applied tensile strains in and out of the LSZ in Fig. 7g. It is clearly observed that the mean KAM values are much higher in the LSZ than those out of the LSZ throughout the entire tensile deformation. This observation indicates that the GND density and the strain gradient adjacent to the interface should be much higher in the LSZ than those out of the LSZ throughout the entire tensile deformation, which confirms the aforementioned and proposed conclusion that the strain partitioning between 304 SS and low C steel is more significant in the LSZ than that out of the LSZ.

TEM pictures for the 304 SS on the surface and out of the LSZ after tensile deformation are displayed in Fig. 8. Fig. 8a shows the martensite phase (indicated by the SAD pattern of the inset) after phase
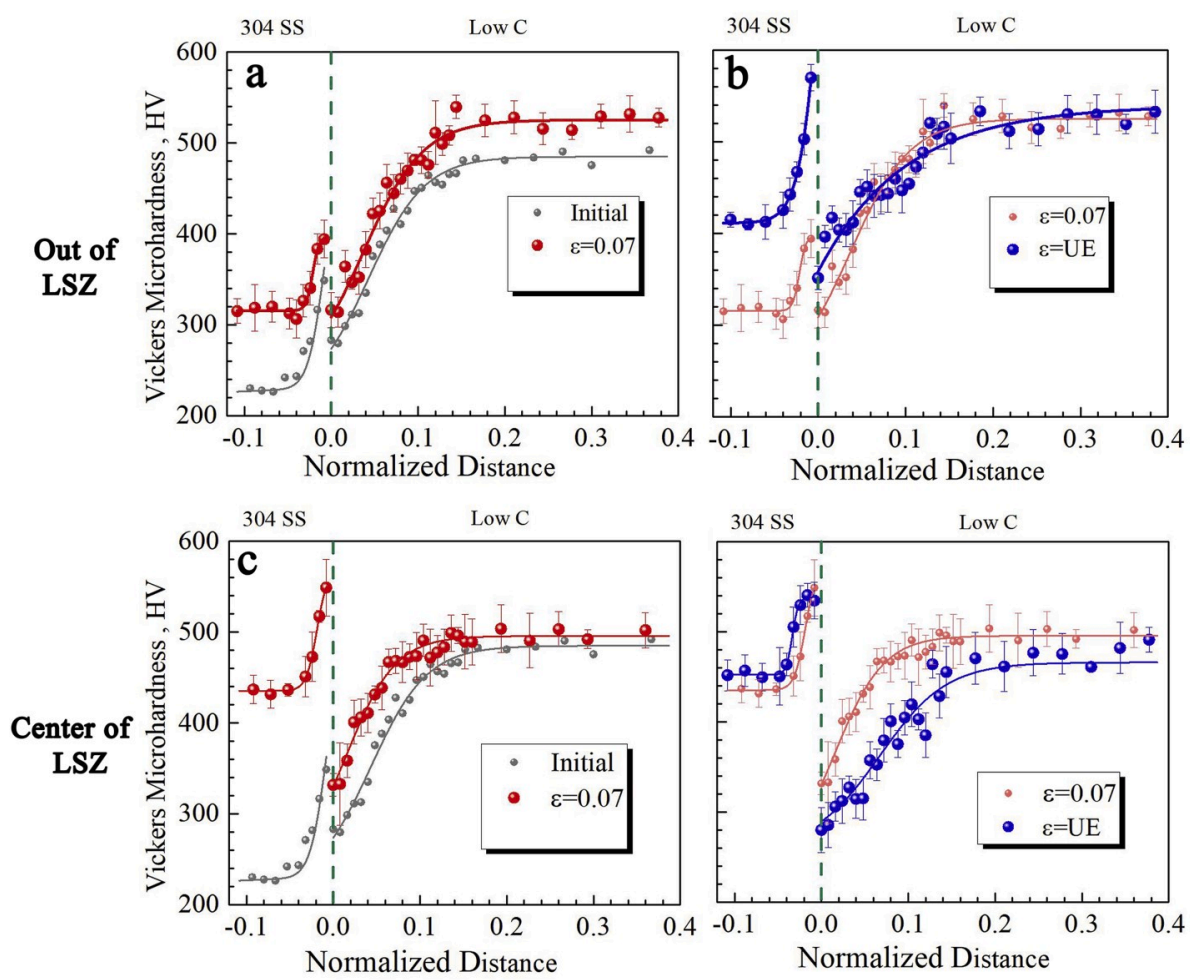

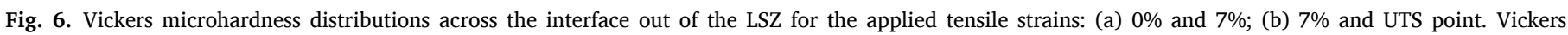
microhardness distributions across the interface in the LSZ for the applied tensile strains: (a) $0 \%$ and $7 \%$; (b) 7\% and UTS point. 

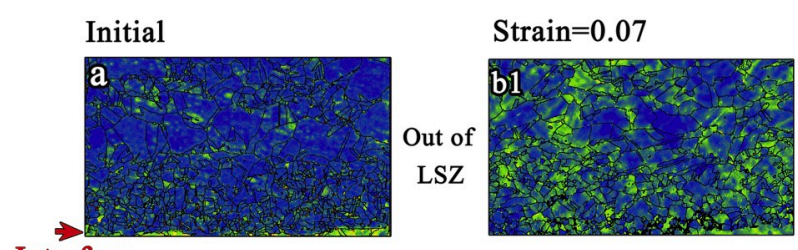

Interface
Strain $=0.18$

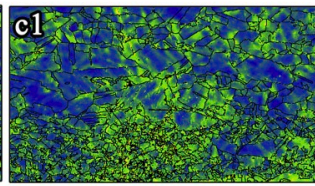

Strain $=\mathrm{UE}$

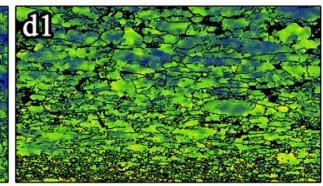

$\operatorname{KAM}\left({ }^{\circ}\right)$

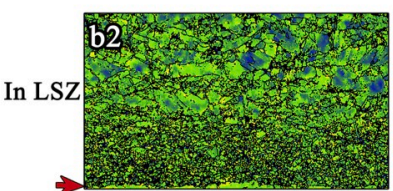

Interface
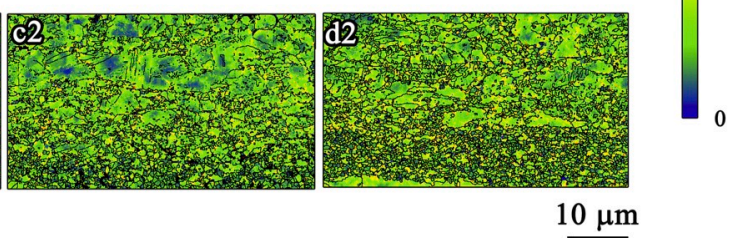
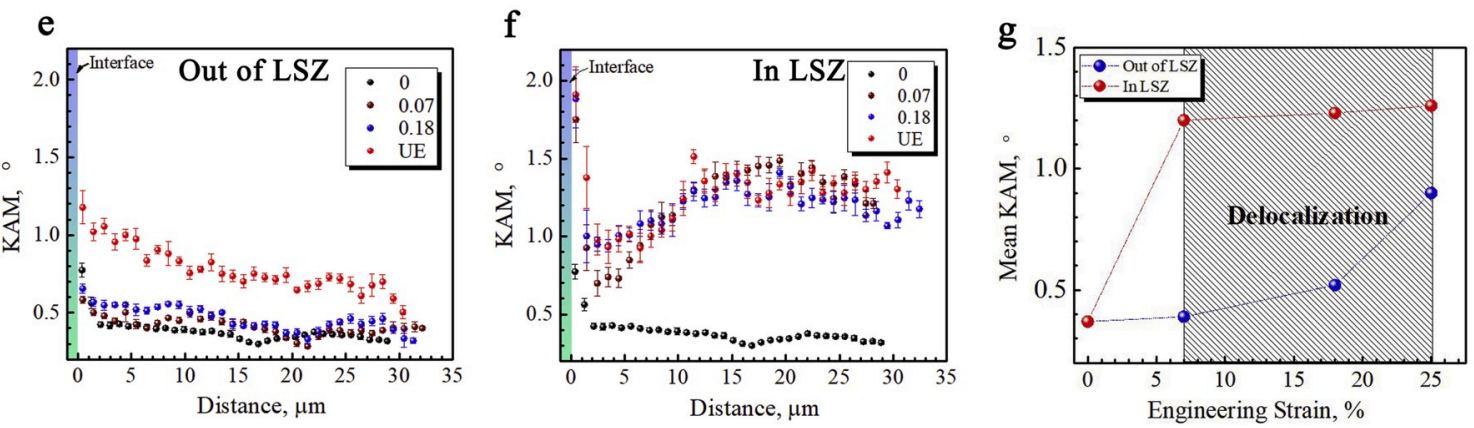

Fig. 7. The KAM distributions in the $304 \mathrm{SS}$ at the area close to the interface in and out of the LSZ. (a) The initial KAM distribution map for the undeformed sample; (b1-d1) The KAM distribution maps out of the LSZ at varying applied tensile strains; (b2-d2) The KAM distribution maps in the LSZ at varying applied tensile strains; (e) (f) The averaged KAM values as a function of the distance from the interface at varying applied tensile strains in and out of the LSZ, respectively; (g) The mean KAM values for the whole map as a function of applied tensile strains in and out of the LSZ.

transformation, and the average size of martensite grains is several hundreds of $\mathrm{nm}$. The transformation-induced plasticity (TRIP) effect and the nanoscale grain size of the martensite phase can have a great positive impact on the strain hardening behavior of 304 SS [54]. Multiple deformation twins (DTs) with twin boundary (TB) spacing of several hundreds of nm at two different slip systems can be clearly observed in Fig. 8b, and the TBs for multiple DTs are not coherent due to the accumulation of dislocations near the TBs. It has been reported that the interactions between dislocations and TBs in FCC metals can have three different ways due to the different relative orientations of the incoming dislocations, and two of them can contribute to strain hardening [55]. In general, the volume fraction of twins increases with the increasing tensile strain. Thus, the strong strain hardening as indicated by the hardness increment at the side of 304 SS can be attributed partly to the formation of DTs and the dislocations behaviors near the TBs. It has also been reported that multiple nanotwins with different slip systems and orientations can further enhance the tensile properties in metals and alloys with low SFE when compared to the single nanotwins, since hierarchical twins are more effective in obstructing dislocation movement and in accumulating dislocations [56-58]. It has also been observed that the DTs and the martensite phase with high density of dislocations can be formed at the same area, as indicated by the TEM picture in Fig. 8c.

TEM pictures for the low $\mathrm{C}$ steel at the center of the samples in and out of the LSZ at two different applied tensile strains (10\% and $25 \%$ ) are displayed in Fig. 9a-d. As indicated in these TEM pictures, lath martensite are all observed, and the average widths of lath martensite in and out of the LSZ are plotted as a function of applied tensile strains in Fig. 9e. The average width of lath martensite was found to decrease with increasing applied tensile strain out of the LSZ until the UTS point, while the average width of lath martensite in the LSZ was observed to decrease with increasing applied tensile strain until $10 \%$ and then start to slightly increase with increasing applied tensile strain afterwards (which is due to the change of strain path and stress state $[27,51]$ by the propagation of LSZ along the gage length). These observation indicate that the size of lath martensite is refined under tensile deformation at cryogenic
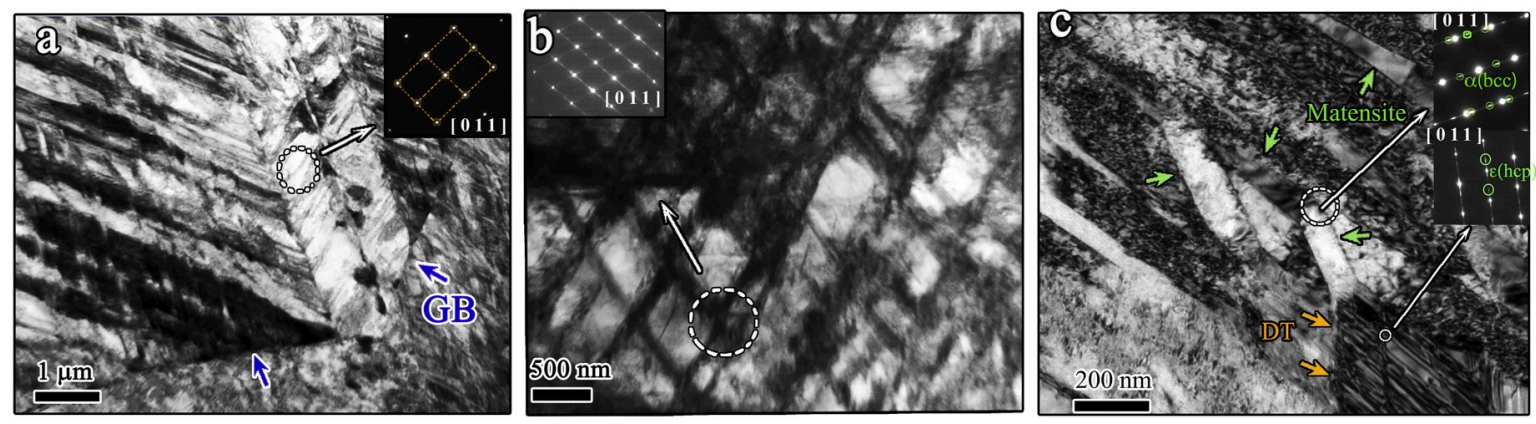

Fig. 8. TEM observations for the $304 \mathrm{SS}$ on the surface and out of the LSZ after tensile deformation (UTS point): (a) Martensite transformation; (b) Multiple DTs; (c) Mixed DTs and martensite phase with high density of dislocations at the same area. 

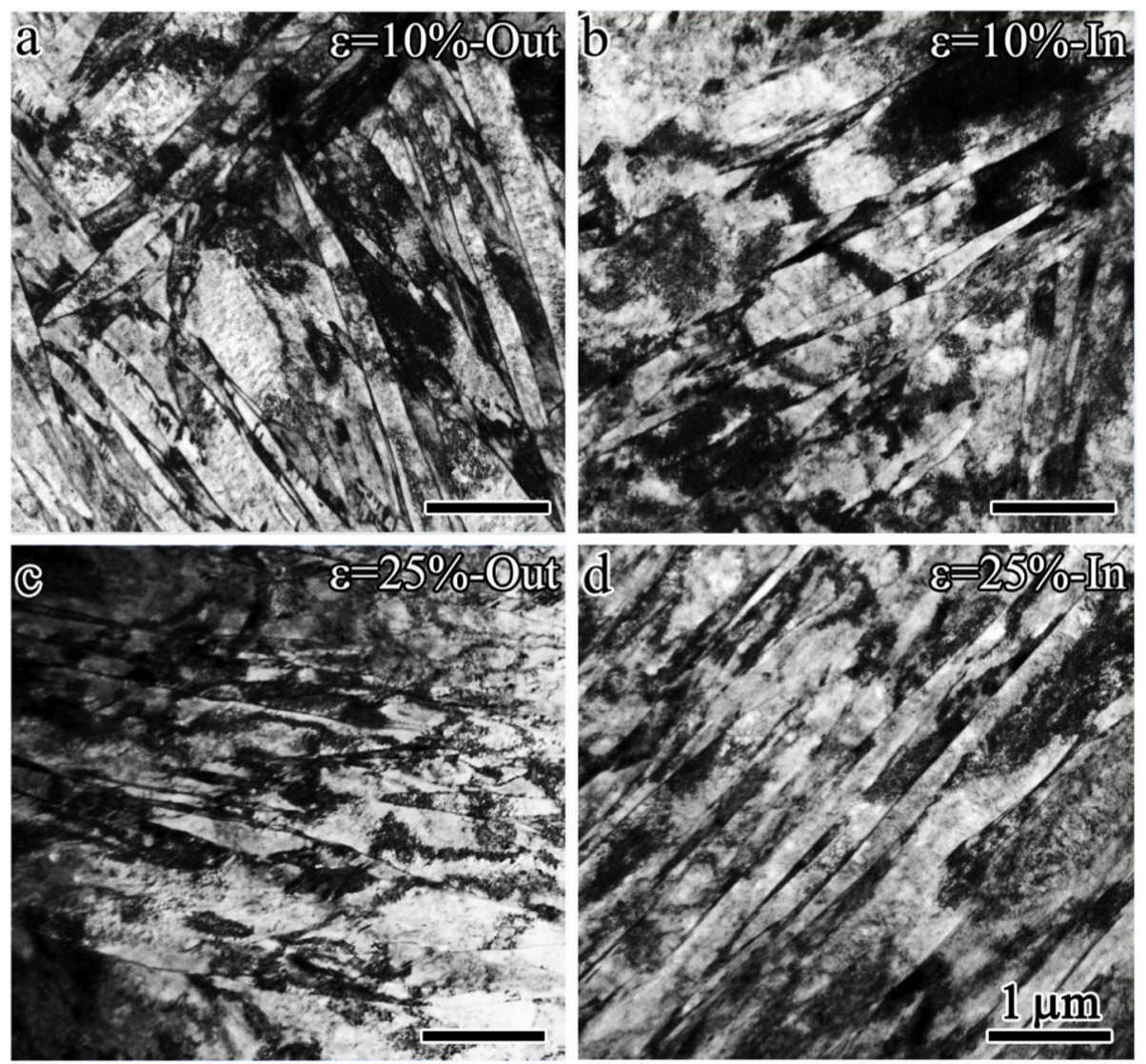

e

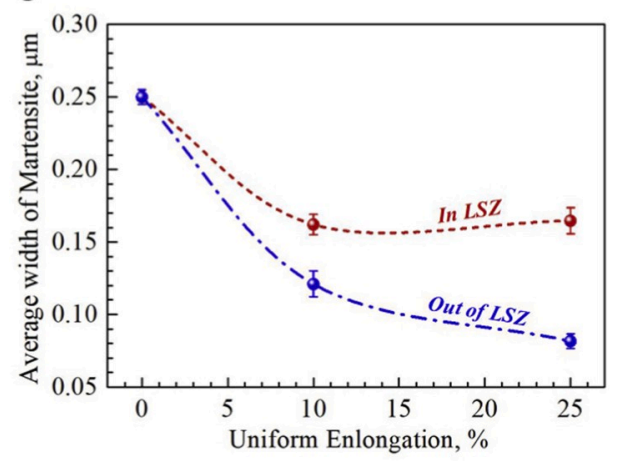

Fig. 9. TEM observations for the low C steel out of the LSZ at two different applied tensile strains: (a) 10\%; (c) 25\%. TEM observations for the low C steel in the LSZ at two different applied tensile strains: (b) $10 \%$; (d) $25 \%$. (e) The average widths of lath martensite in and out of the LSZ as a function of applied tensile strains.

temperature. This grain refinement should contribute to the strain hardening in the martensite phase under tensile deformation at cryogenic temperature, which is very similar to the hardening in twinning-induced plasticity (TWIP) steels by DTs (so called dynamic H-P effect in TWIP steels) [54]. It also should be noted that the grain refinement out of the LSZ is more severe than that in the LSZ, which further confirms that the strain partitioning between 304 SS and low C steel is more significant in the LSZ (the low C steel in the LSZ carries much less strain) than that out of the LSZ.

\section{Concluding remarks}

In the present study, the low C martensite steel/304 austenite SS laminate was fabricated by hot-rolling followed by annealing and water quenching, and then the tensile behaviors and the corresponding deformation mechanisms of the laminate under both cryogenic and room temperatures were investigated by a novel tensile testing method coupled with in-situ DIC imaging and subsequent microstructure observations (EBSD, XRD, and TEM), the main findings are summarized as follows:

(1) Generally, CG 304 austenite SS has a higher yield strength and a lower uniform elongation, while low C martensite steel has a higher yield strength and a slightly larger uniform elongation, under cryogenic temperature when compared to these under room temperature. However, the heterogeneous laminate was found to show simultaneously much higher yield strength and significantly larger uniform elongation under cryogenic temperature when compared to those under room temperature, exhibiting superior cryogenic tensile properties.

(2) The low $C$ steel in the laminate has lower strain hardening ability, thus strain localization was observed to be formed first in the low C steel, and then the LSZ was found to propagate across the interface to the 304 SS side. While this LSZ was not exacerbated 
to cause severe necking and fracture, and delocalization was found to occur in the LSZ with increasing applied tensile strain due to the propagation of LSZ towards the un-deformed region along the gage length.

(3) The severity of strain concentration in the LSZ was found to be reduced after $10 \%$ of applied tensile strain due to the concentrated martensite transformation and the enhanced strain hardening ability in the LSZ. Thus the strain delocalization in the LSZ can be attributed to the non-uniform martensite transformation along the gage length, resulting in large tensile ductility in the laminate under cryogenic temperature. Moreover, strain partitioning between 304 SS and low C steel was found to be more significant in the LSZ than that out of the LSZ. Thus, higher density of GNDs should be accumulated in the LSZ to reduce the severity of strain localization for improving ductility.

(4) After cryogenic tensile deformation (up to UTS point), high fraction of martensite phase and high density of multiple deformation nanotwins were found to be formed in the grain interiors of 304 SS, resulting in strong strain hardening and large tensile ductility in the laminates under cryogenic temperature. Cryogenic deformation-induced grain refinement should contribute to the strain hardening in the low $\mathrm{C}$ steel.

\section{Data availability}

The processed data required to reproduce these findings cannot be shared at this time due to technical or time limitations.

\section{Declaration of competing interest}

The authors declare that they have no known competing financial interests or personal relationships that could have appeared to influence the work reported in this paper.

\section{CRediT authorship contribution statement}

Jinyan He: Investigation. Fuping Yuan: Conceptualization, Writing - original draft, Supervision. Muxin Yang: Investigation. Lingling Zhou: Investigation. Sihai Jiao: Resources. Xiaolei Wu: Conceptualization, Supervision.

\section{Acknowledgements}

This work was supported by the NSFC Basic Science Center Program for "Multiscale Problems in Nonlinear Mechanics" [grant number 11988102]; the National Key R\&D Program of China [grant number 2017YFA0204402]; the National Natural Science Foundation of China [grant numbers 11672313 and 11572328], and the Strategic Priority Research Program of the Chinese Academy of Sciences [grant numbers XDB22040503].

\section{References}

[1] J. Lee, S.S. Sohn, S. Hong, B.-C. Suh, S.-K. Kim, B.-J. Lee, N.J. Kim, S. Lee, Effects of $\mathrm{Mn}$ addition on tensile and charpy impact properties in austenitic Fe-Mn-C-Albased steels for cryogenic applications, Metall. Mater. Trans. A 45A (2014) 5419-5430.

[2] M. Koyama, T. Lee, C.S. Lee, K. Tsuzaki, Grain refinement effect on cryogenic tensile ductility in a Fe-Mn-C twinning-induced plasticity steel, Mater. Des. 49 (2013) 234-241.

[3] Z.W. Ma, Y. Ren, R.G. Li, Y.-D. Wang, L.L. Zhou, X.L. Wu, Y.J. Wei, H.J. Gao, Cryogenic temperature toughening and strengthening due to gradient phase structure, Mater. Sci. Eng., A 712 (2018) 358-364.

[4] S.S. Sohn, S. Hong, J. Lee, B.-C. Suh, S.-K. Kim, B.-J. Lee, N.J. Kim, S. Lee, Effects of $\mathrm{Mn}$ and Al contents on cryogenic-temperature tensile and Charpy impact properties in four austenitic high-Mn steels, Acta Mater. 100 (2015) 39-52.

[5] Y.H. Wang, B.D. Shi, Y.M. He, H.W. Zhang, Y. Peng, T.S. Wang, A fine grain, high Mn steel with excellent cryogenic temperature properties and corresponding constitutive behaviour, Materials 11 (2018) 253.
[6] J. Yoo, K. Choi, A. Zargaran, N.J. Kim, Effect of stacking faults on the ductility of Fe-18Mn-1.5Al-0.6C twinning-induced plasticity steel at low temperatures, Scripta Mater. 137 (2017) 18-21.

[7] Y. Li, Y.F. Lu, W. Li, M. Khedr, H.B. Liu, X.J. Jin, Hierarchical microstructure design of a bimodal grained twinning-induced plasticity steel with excellent cryogenic mechanical properties, Acta Mater. 158 (2018) 79-94.

[8] J.-H. Kim, S.-K. Kim, M.-H. Kim, J.-M. Lee, Numerical model to predict deformation of corrugated austenitic stainless steel sheet under cryogenic temperatures for design of liquefied natural gas insulation system, Mater. Des. 57 (2014) 26-39.

[9] W.S. Park, S.W. Yoo, M.H. Kim, J.M. Lee, Strain-rate effects on the mechanical behavior of the AISI 300 series of austenitic stainless steel under cryogenic environments, Mater. Des. 31 (2010) 3630-3640.

[10] J. Liu, D. Kaoumi, Use of in-situ TEM to characterize the deformation-induced martensitic transformation in 304 stainless steel at cryogenic temperature, Mater. Char. 136 (2018) 331-336.

[11] P. Czarkowski, A.T. Krawczyńska, T. Brynk, M. Nowacki, M. Lewandowska, K. J. Kurzydłowski, Cryogenic strength and microstructure of a hydrostatically extruded austenitic steel 1.4429 (AISI 316LN), Cryogenics 64 (2014) 1-4.

[12] P. Czarkowski, A.T. Krawczynska, R. Slesinski, T. Brynk, J. Budniak, M. Lewandowska, K.J. Kurzydlowski, Low temperature mechanical properties of 316L type stainless steel after hydrostatic extrusion, Fusion Eng. Des. 86 (2011) 2517-2521.

[13] P. Deimel, H. Fischer, M. Hoffmann, Strength and toughness properties of two nitrogen alloyed stainless steels and their submerged arc weldments at cryogenic temperatures, J. Mater. Sci. 33 (1998) 1105-1116.

[14] M. Hauser, M. Wendler, O. Fabrichnaya, O. Volkova, J. Mola, Anomalous stabilization of austenitic stainless steels at cryogenic temperatures, Mater. Sci. Eng., A 675 (2016) 415-420.

[15] H.M. Ding, Y.Z. Wu, Q.J. Lu, P. Xu, J.Y. Zheng, L.J. Wei, Tensile properties and impact toughness of S30408 stainless steel and its welded joints at cryogenic temperatures, Cryogenics 92 (2018) 50-59.

[16] Y.Q. Lu, H. Hui, Investigation on mechanical properties of S30403 austenitic stainless steel at different temperatures, J. Pressure Vessel Technol. 140 (2018), 024502.

[17] K.J. Lee, M.S. Chun, M.H. Kim, J.M. Lee, A new constitutive model of austenitic stainless steel for cryogenic applications, Comput. Mater. Sci. 46 (2009) 1152-1162.

[18] J. Xie, X.Q. Zhao, J.-B. Yan, Mechanical properties of high strength steel strand at low temperatures: Tests and analysis, Construct, Building Mater 189 (2018) 1076-1092.

[19] N. Uehata, M. Koyama, S. Takagi, K. Tsuzaki, Optical microscopy-based damage quantification: an example of cryogenic deformation of a dual-phase steel, ISIJ Int. 58 (2018) 179-185.

[20] M.A. Meyers, A. Mishra, D.J. Benson, Mechanical properties of nanocrystalline materials, Prog. Mater. Sci. 51 (2006) 427-556.

[21] R.Z. Valiev, Nanostructuring of metals by severe plastic deformation for advanced properties, Nat. Mater. 3 (2004) 511-516.

[22] Y.M. Wang, M.W. Chen, F.H. Zhou, E. Ma, High tensile ductility in a nanostructured metal, Nature 419 (2002) 912-915.

[23] P.V. Liddicoat, X.Z. Liao, Y.H. Zhao, Y.T. Zhu, M.Y. Murashkin, E.J. Lavernia, R. Z. Valiev, S.P. Ringer, Nanostructural hierarchy increases the strength of aluminum alloys, Nat. Commun. 1 (2010) 63.

[24] X.L. Wu, M.X. Yang, F.P. Yuan, G.L. Wu, Y.J. Wei, X.X. Huang, Y.T. Zhu, Heterogeneous lamella structure unites ultrafine grain strength with coarse-grain ductility, Proc. Natl. Acad. Sci. U.S.A. 112 (2015) 14501-14505.

[25] Y.H. Zhao, T. Topping, J.F. Bingert, J.J. Thornton, A.M. Dangelewicz, Y. Li, W. Liu, Y.T. Zhu, Y.Z. Zhou, E.L. Lavernia, High tensile ductility and strength in bulk nanostructured nickel, Adv. Mater. 20 (2008) 3028-3033.

[26] T.H. Fang, W.L. Li, N.R. Tao, K. Lu, Revealing extraordinary intrinsic tensile plasticity in gradient nano-grained copper, Science 331 (2011) 1587-1590.

[27] X.L. Wu, P. Jiang, L. Chen, F.P. Yuan, Y.T. Zhu, Extraordinary strain hardening by gradient structure, Proc. Natl. Acad. Sci. U.S.A. 111 (2014) 7197-7201.

[28] Y.J. Wei, Y.Q. Li, L.C. Zhu, Y. Liu, X.Q. Lei, G. Wang, Y.X. Wu, Z.L. Mi, J.B. Liu, H. T. Wang, H.J. Gao, Evading the strengthductility trade-off dilemma in steel through gradient hierarchical nanotwins, Nat. Commun. 5 (2014) 3580.

[29] F.P. Yuan, D.S. Yan, J.D. Sun, L.L. Zhou, Y.T. Zhu, X.L. Wu, Ductility by shear band delocalization in the nano-layer of gradient structure, Mater. Res. Let. 7 (2019) $12-17$.

[30] X.L. Wu, Y.T. Zhu, Heterogeneous materials: a new class of materials with unprecedented mechanical properties, Mater. Res. Lett. 5 (2017) 527-532.

[31] E. Ma, T. Zhu, Towards strength-ductility synergy through the design of heterogeneous nanostructures in metals, Mater. Today 20 (2017) 323-331.

[32] X.L. Ma, C.X. Huang, W.Z. Xu, H. Zhou, X.L. Wu, Y.T. Zhu, Strain hardening and ductility in a coarse-grain/nanostructure laminate material, Scripta Mater. 103 (2015) 57-60.

[33] X.L. Ma, C.X. Huang, J. Moering, M. Ruppert, H.W. Höppel, M. Göken, J. Narayan, Y.T. Zhu, Mechanical properties of copper/bronze laminates: Role of interfaces, Acta Mater. 116 (2016) 43-52.

[34] J.Y. He, Y. Ma, D.S. Yan, S.H. Jiao, F.P. Yuan, X.L. Wu, Improving ductility by increasing fraction of interfacial zone in low C steel/304 SS laminates, Mater. Sci. Eng., A 726 (2018) 288-297.

[35] C.X. Huang, Y.F. Wang, X.L. Ma, S. Yin, H.W. Höppel, M. Göken, X.L. Wu, H.J. Gao, Y.T. Zhu, Interface affected zone for optimal strength and ductility in heterogeneous laminate, Mater. Today 21 (2018) 713-719. 
[36] M. Ojima, J. Inoue, S. Nambu, P. Xu, K. Akita, H. Suzuki, T. Koseki, Stress partitioning behavior of multilayered steels during tensile deformation measured by in situ neutron diffraction, Scripta Mater. 66 (2012) 139-142.

[37] H. Wu, G.H. Fan, M. Huang, L. Geng, X.P. Cui, H.L. Xie, Deformation behavior of brittle/ductile multilayered composites under interface constraint effect, Int. J. Plast. 89 (2017) 96-109.

[38] A. Misra, J.P. Hirth, R.G. Hoagland, Length-scale-dependent deformation mechanisms in incoherent metallic multilayered composites, Acta Mater. 53 (2005) $4817-4824$.

[39] A.Y. Chen, D.F. Li, J.B. Zhang, H.W. Song, J. Lu, Make nanostructured metal exceptionally tough by introducing non-localized fracture behaviors, Scripta Mater. 59 (2008) 579-582.

[40] H.S. Liu, B. Zhang, G.P. Zhang, Delaying premature local necking of high-strength Cu: a potential way to enhance plasticity, Scripta Mater. 64 (2011) 13-16.

[41] S. Zheng, I.J. Beyerlein, J.S. Carpenter, K. Kang, J. Wang, W. Han, N.A. Mara, highstrength and thermally stable bulk nanolayered composites due to twin induced interfaces, Nat. Commun. 4 (2013) 1696.

[42] I.J. Beyerlein, J.R. Mayeur, S. Zheng, N.A. Mara, J. Wang, A. Misra, Emergence of stable interfaces under extreme plastic deformation, Proc. Natl. Acad. Sci. 111 (2014) 4386-4390.

[43] H. Wu, B.C. Jin, L. Geng, G.H. Fan, X.P. Cui, M. Huang, R.M. Hicks, S. Nutt, Ductilephase toughening in TiBw/Ti-Ti3Al metallic-intermetallic laminate composites, Metall. Mater. Trans. A 46A (2015) 3803-3807.

[44] R. Yuan, I.J. Beyerlein, C.Z. Zhou, Homogenization of plastic deformation in heterogeneous lamella structures, Mater. Res. Let. 5 (2017) 251-257.

[45] J.Y. He, F.P. Yuan, M.X. Yang, S.H. Jiao, X.L. Wu, Superior mechanical properties and deformation mechanisms of heterogeneous laminates under dynamic shear loading, Mater. Sci. Eng., A 756 (2019) 492-501.

[46] H.C. Zhang, D. Xu, R.J. Huang, C.J. Huang, H.M. Liu, Y.M. Han, L.F. Li, Liquid helium free mechanical property test system with G-M cryocoolers, Cryogenics 85 (2017) 58-62.
[47] Y. Ma, M.X. Yang, P. Jiang, F.P. Yuan, X.L. Wu, Plastic deformation mechanisms in a severely deformed Fe-Ni-Al-C alloy with superior tensile properties, Sci. Rep. 7 (2017) 15619.

[48] X.L. Wu, M.X. Yang, F.P. Yuan, L. Chen, Y.T. Zhu, Combining gradient structure and TRIP effect to produce austenite stainless steel with high strength and ductility, Acta Mater. 112 (2016) 337-346.

[49] J.-B. Seol, J.E. Jung, Y.W. Jang, C.G. Park, Influence of carbon content on the microstructure, martensitic transformation and mechanical properties in austenite/ ع-martenite dual-phase Fe-Mn-C steels, Acta Mater. 61 (2013) 558-578.

[50] S.M.C. van Bohemen, Bainite and martensite start temperature calculated with exponential carbon dependence, Mater. Sci. Tech-lond. 28 (2012) 487-495.

[51] D.V. Wilson, Influences of cell-walls and grain-boundaries on transient responses of an IF steel to changes in strain path, Acta Metall. Mater. 42 (1994) 1099-1111.

[52] H. Gao, Y. Huang, W.D. Nix, J.W. Hutchinson, Mechanism-based strain gradient plasticity - I. Theory, J. Mech. Phys. Solid. 47 (1999) 1239-1263.

[53] L.P. Kubin, A. Mortensen, Geometrically necessary dislocations and strain gradient plasticity: a few critical issues, Scripta Mater. 48 (2003) 119-125.

[54] O. Grässel, L. Krüger, G. Frommeyer, L.W. Meyer, High strength Fe-Mn-(Al, Si) TRIP/TWIP steels development-properties-application, Int. J. Plast. 16 (2000) 1391-1409.

[55] L. Lu, Z.S. You, K. Lu, Work hardening of polycrystalline Cu with nanoscale twins, Scripta Mater. 66 (2012) 837-842.

[56] Y. Ma, M.X. Yang, F.P. Yuan, X.L. Wu, A review on heterogeneous nanostructures: A strategy for superior mechanical properties in metals, Metals 9 (2019) 598.

[57] X.W. Liu, L.G. Sun, L.L. Zhu, J.B. Liu, K. Lu, J. Lu, High-order hierarchical nanotwins with superior strength and ductility, Acta Mater. 149 (2018) 397-406.

[58] Y. Ma, F.P. Yuan, M.X. Yang, P. Jiang, E. Ma, X.L. Wu, Dynamic shear deformation of a CrCoNi medium-entropy alloy with heterogeneous grain structures, Acta Mater. 148 (2018) 407-418. 